\title{
SANEAMENTO BÁSICO: UMA AVALIAÇÃO SOBRE A ATUAÇÃO DOS SETORES PÚBLICO E PRIVADO NO CONTEXTO DE NOVAS PROPOSIÇÕES REGULATÓRIAS
}

\author{
BASIC SANITATION: AN ASSESSMENT OF PUBLIC AND PRIVATE SECTOR PERFORMANCE IN THE CONTEXT OF NEW \\ REGULATORY PROPOSITIONS
}

\section{RESUMO}

O texto analisa a atuação dos setores público e privado na política de saneamento na segunda década do século XXI, tendo em vista, a retomada das discussões sobre privatização dos serviços. Para conduzir essa tarefa foi feita revisão bibliográfica para a recuperação da trajetória da política pública, análise dos dados do Sistema Nacional de Informações sobre Saneamento (SNIS) para produzir um diagnóstico do setor, e o estudo de documentos, discursos e estratégias dos principais atores sociais para uma avaliação crítica das propostas de rediscussão do marco regulatório nacional. Além de introdução e considerações finais, o trabalho foi dividido em mais três seções. A primeira apresenta uma síntese da trajetória da política no país. A seguinte introduz um diagnóstico sobre a atuação pública e privada na segunda década do século XXI. E, no terceiro momento, recupera a discussão sobre a ampliação da incidência da iniciativa privada no setor a partir das transformações regulatórias experimentadas. O estudo conclui que, mesmo após o fim do Planasa, estruturas centralizadoras foram mantidas, deslocado o protagonismo sobre a política da União para os estados. As alianças formadas entre estadualistas e municipalistas foram eficientes em manter minoritária a participação da iniciativa privada, por outro lado, também evitaram a descentralização do sistema. Ante a retomada das propostas de privatização, não está claro se a recuperação de tais alianças será suficiente para bloquear as novas tentativas de ampliar a participação privada. Entretanto, sustenta-se que qualquer alteração substantiva no modelo dependerá da produção de consensos que incluam os referidos atores.

Palavras-chave: política pública; saneamento básico; gestão pública; privatização.

\begin{abstract}
The text analyzes public and private sectors performance in the sanitation policy in the second decade of the 21st century, considering the resumption of discussions about the services privatization. To perform this task, a literature review was conducted to recover the policy trajectory, the analysis of data from the National Sanitation Information System (SNIS) was made to develop the sector's diagnosis, and the study of documents, discourses and strategies of the main social actors was done for an evaluation of the proposals rediscussing the national regulatory framework. In addition to an introduction and concluding observations, the paper was divided into three sections. The first presents a synthesis of the policy trajectory in Brazil. The following introduces a diagnosis of public and private sectors performance in the second decade of the 21st century. And, in the third moment, it recovers the discussion about the increased incidence of private sector from the regulatory transformations experienced. The study concludes that, even after the end of Planasa, centralizing structures were maintained, displacing the protagonism of the Union over the policy towards the states. Alliances between stateists and municipalists were effective in keeping reduced the private initiative participation, on the other hand, also prevented system's decentralization. Given the resurgence of privatization proposals, it is not clear whether the recovery of such alliances will be sufficient to block further attempts to expand private participation. However, it is argued that any substantive change in the current model will depend on a consensus that includes these actors.
\end{abstract}

Keywords: public policy; basic sanitation; public Management; privatization.
Pedro Henrique Ramos Prado Vasques $^{\text {a }}$

a Universidade do Estado do Rio de Janeiro (UERJ), Rio de Janeiro, RJ, Brasil

DOI: 10.12957/geouerj.2020.48413

Correpondência: pedrohvasques@gmail.com

Recebido em: 19 set. 2019 Revisado em: 22 out. 2019

Aceito em: 16dez.2019 


\section{INTRODUÇÃO}

O presente trabalho se propõe a conduzir uma avaliação sobre a atuação dos setores público e privado na política de saneamento na segunda década do século XXI, tendo em vista a ressurgência da discussão sobre privatização dos serviços de abastecimento de água e esgotamento sanitário. Para fazê-lo, as etapas de pesquisa envolveram a recuperação da trajetória da política por meio da bibliografia, a análise dos dados produzidos pelo Sistema Nacional de Informações sobre Saneamento (SNIS), e a avaliação crítica dos documentos, discursos e estratégias dos principais atores sociais envolvidos nos processos recentes de rediscussão do marco regulatório nacional vigente. Dessa forma, o texto foi dividido em três seções, descritas a seguir, para além dessa introdução e de considerações finais sobre a temática desenvolvida.

A primeira seção apresenta uma síntese da trajetória da política de saneamento no país. As observações incluem desde a República Velha, passando pela Era Vargas, o período democrático de 1946-64, e o período do regime militar, que é analisado com ênfase. Isso porque, é nesse momento que a política ganha prioridade no âmbito nacional a partir do Plano Nacional de Saneamento (Planasa), modelo esse cujo legado remanesce presente nas instituições. Em seguida, trata dos desdobramentos da redemocratização associados ao saneamento, as incertezas institucionais e regulatórias, bem como a assunção do protagonismo dos estados. Por fim, introduz comentários sobre a aprovação do marco regulatório nacional durante o primeiro governo Lula.

A seção seguinte se propõe a introduzir um diagnóstico sobre a atuação pública e privada no setor na segunda década do século XXI. Nesse contexto, trabalha os dados de forma crítica tanto à luz das disputas entre público e privado, mas também considerando a dinâmica entre as gestões estaduais e municipais. Ao final desenvolve ainda observações tendo em vista tanto a dimensão nacional dessas dinâmicas, como suas implicações regionais. Nesse contexto, verifica-se que o setor vem resistindo à privatização apesar da manutenção hegemônica dos governos estaduais sobre o tema, que ainda se vale das estruturas legadas pelo Planasa.

No terceiro estágio, o texto recupera o debate sobre a construção de um marco regulatório nacional a partir da derrocada do Planasa e da promulgação da Constituição Federal de 1988. Dessa forma, aborda as disputas no entorno das propostas apresentadas pelo governo durante a década de 1990, incluindo a emergência de um movimento de resistência às privatizações estimuladas pelo modelo. Adiante, desenvolve o debate no entorno do projeto de lei que veio a se tornar a Lei n. $11.445 / 2007$, e os conflitos entre estadualistas e municipalistas na conformação da estrutura regulatória. Por fim, trata da retomada da discussão sobre alteração da regulação nacional e a ressurgência das propostas de privatização dos serviços, bem como a recomposição da resistência organizada para impedir a aprovação de projetos similares anteriormente apresentados. 
O trabalho avalia que o fim do Planasa deslocou o controle centralizado na União para os estados que, desde então, vêm conduzindo a política com protagonismo. As alianças formadas entre estadualistas e municipalistas para resistir à ampliação da participação privada no setor vem se mostrando fundamentais para manutenção do sistema. Por outro lado, as tentativas de descentralizar a gestão da política, mitigando o protagonismo dos estados, restaram também inviabilizadas. Entretanto, no contexto de crise políticofinanceira, deflagrado a partir de 2014, há uma retomada das propostas de privatização dos serviços de água e esgoto que, novamente, vêm sendo combatidas pelos grupos formados na década de 1990. Por outro lado, ainda que não esteja claro se essa resistência será suficiente para bloquear por completo essas novas tentativas, é muito provável que alterações no modelo regulatório vigente, em especial, para ampliar a participação privada no setor, dependerão da produção de consensos que necessariamente envolvam os atores sociais diretamente relacionados à política pública.

\section{Uma síntese da trajetória da política pública no Brasil}

Ainda que para parte da literatura não fosse possível enquadrar os serviços de água e esgoto no Brasil em um padrão uniforme até o início do regime militar (Turolla, 2002), identifica-se em alguns trabalhos um exercício de síntese do período que pode ser útil à compreensão da trajetória da política pública. Segundo Santos (1993) e Oliveira \& Sanchez (1997), durante a República Velha (1889-1930), o saneamento - cujo conteúdo também sofreu transformações ao longo do século XX - tratava-se de um serviço de competência local, administrado por companhias privadas, mas com expressiva presença de recursos públicos, e cujo atendimento restringia-se a áreas de maior rentabilidade. Entre 1930-45, durante a Era Vargas, os autores identificam uma mudança na direção da centralização da política, ficando sua execução sob responsabilidade do Departamento Nacional de Obras e Saneamento (DNOS), sem incentivos à gestão local. A despeito de terem sido desenvolvidas grandes obras no período, este é marcado pela desvinculação dos valores das tarifas em relação aos investimentos realizados. Destacam, ainda, a importância no período da Fundação Serviços de Saúde Pública (FSESP) cuja orientação se deu a partir de acordos celebrados entre Brasil e Estados Unidos para atuação na área de saúde pública em regiões estratégicas do país, como, por exemplo, na amazônica, e nos Estados do Espírito Santo e Minas Gerais. No período de redemocratização, entre 1946-64, retoma-se a municipalização dos serviços de água e esgoto, lastreados por investimentos federais e estaduais definidos a partir de coalizões políticas que, nem sempre, refletiam as demandas colocadas pela intensificação do processo de urbanização brasileiro.

A gestão municipal da política pública, sob supervisão da Fundação Nacional de Saúde (Funasa), remanesce até o começo da década de 1970, momento no qual, em virtude da instalação do regime militar, há uma significativa mudança nos rumos do saneamento no país. Importante salientar que, apesar da 
descentralização até então vigente, a política era de fato implementada apenas nos municípios que possuíam os recursos necessários para tanto, o que contribuía para a heterogeneidade de acesso ao saneamento básico (Braga et al., 1995). Segundo Turolla (2002), o governo militar havia elegido a ampliação da cobertura da política pública com uma de suas prioridades, o que se encontrava alinhado ao projeto desenvolvimentista que preconizava a centralização política e administrativa como estratégia institucional para o desenvolvimento de sua atuação (Oliveira \& Sanchez, 1997). Nesse cenário, o Banco Nacional de Habitação (BNH) foi encarregado, em 1967, de realizar o diagnóstico inicial da situação do setor de saneamento no país como uma complementação à política habitacional do Banco. A partir de então, uma série de instituições foram criadas - dentre elas, os fundos e as companhias estaduais - com o objetivo de colocar em prática o Plano Nacional de Saneamento (Planasa) que, formalmente criado em 1971, era responsável por todo o planejamento de investimentos no setor, assim como as políticas de tarifas, crédito etc. (Motta, 2004). Ademais, tinha como ambição ampliar o atendimento urbano à água aos $80 \%$ e a esgoto aos 50\% até 1980. O Plano, por sua vez, era gerido pelo Ministério do Interior e financiado pelo $\mathrm{BNH}$, mais especificamente, pelo Sistema Financeiro de Saneamento (SFS) que passou a centralizar recursos e a coordenar ações.

Como estratégia de indução para que os municípios aderissem ao Planasa, e sob o discurso da incapacidade financeira e política dos gestores locais para lidar com as demandas de águas e esgotos, o governo adotou duas principais condutas. A primeira, tratava-se do oferecimento de cotas de participação acionária nas companhias estaduais em troca da incorporação de ativos locais já instalados e em operação existentes principalmente em municípios mais populosos e melhor estruturados (Oliveira \& Sanchez, 1997). A segunda, buscou limitar às companhias estaduais os empréstimos fornecidos pelo BNH, implicando que os municípios só poderiam acessar tais recursos se concedessem o serviço de saneamento aos Estados (Nozaki, 2007). Mesmo considerando as resistências observadas, que chegaram a incluir políticos de sustentação do próprio governo, segundo Motta (2004), cerca de 3.200 municípios dos então 4.100 aderiram ao Planasa, conferindo êxito à estratégia centralizadora conduzida pelo regime militar. De qualquer modo, o que parecia ser um alívio para os prefeitos de municípios pequenos, acabou se mostrando o contrário, uma vez que os recursos foram prioritariamente investidos em áreas mais populosas (notadamente, regiões Sudeste e Sul) visando o ganho de escala e, em especial, para o abastecimento de água em detrimento do tratamento de esgoto (Oliveira \& Sanchez, 1997).

Como destaca Nozaki (2007), uma grande peculiaridade do Planasa, e que explicitava a grandeza do programa de financiamento do saneamento básico, era a utilização de recursos do Fundo de Garantia por Tempo de Serviço (FGTS), instituído em 1967 - este representava uma contribuição mensal de 8\% sobre o salário mensal dos trabalhadores. Segundo Braga (et al., 1995), outra importante fonte da política eram os Fundos de Financiamento para Águas e Esgotos (FAE), constituídos por recursos oriundos dos orçamentos dos estados - contrapartida exigida para recebimento dos recursos do FGTS. Nesse sistema, a participação do 
governo federal nos investimentos em água e esgoto era, em tese, limitada à metade do valor necessário, cabendo aos estados e municípios custearem o restante - que, em regra, se dava também com o apoio de organismos multilaterais, como o Banco Mundial, e mediante a contratação de empréstimos. Ocorre que o foco na ampliação do setor, a despeito das despesas de manutenção e operação dos sistemas já existentes, levou a uma deterioração das estruturas aumentando a ineficiência e nível de perdas - o que, até hoje, representa elevada parte dos prejuízos aos prestadores de serviços, inclusive sendo tal situação utilizada como justificativa para a condução de privatizações (Nozaki, 2007).

Apesar de a referida estruturação financeira haver permitido vultuosos investimentos entre 1970 e 1980, passando de 11,9 milhões para 49,6 milhões o número de pessoas atendidas por abastecimento de água e de 6,1 milhões para 17,4 milhões aquelas beneficiadas por sistemas de esgotamento sanitário, tal modelo não se mostrou sustentável. Isso porque, já em meados da década de 1970, as intervenções do governo federal no controle tarifário visando atuar sobre a inflação minaram a capacidade de planejamento e gestão das companhias estaduais (Oliveira \& Sanchez, 1997). Incapacitados de financiar suas políticas por meio das tarifas, observou-se um crescente endividamento público que, ainda que não tenha sido sentido de forma expressiva nos anos 1970, tornou-se um dos principais empecilhos para a continuidade plena do modelo na década seguinte, haja vista, em especial, a deflagração de uma intensa crise econômica nacional e mundial.

Nesse sentido, o baixo potencial de autofinanciamento das companhias estaduais, o esgotamento da sua capacidade de endividamento, as restrições no emprego dos recursos do FGTS - em virtude da recessão e do desemprego -, as dificuldades de captação de apoio multilateral, a má gestão dos recursos do fundo e o intenso e desordenado crescimento da malha urbana - que aumentavam os custos dos investimentos representaram a derrocada do modelo desenvolvido a partir do Planasa. Assim, ainda que no início dos anos 1980 as companhias estaduais não apresentassem condições mínimas para execução de suas atribuições, e tivesse havido uma sensível diminuição dos recursos destinados ao saneamento, entre 1980-84 foi possível verificar avanços na política pública com a ampliação para 63,4 milhões de pessoas no setor de abastecimento de água e 22,5 milhões beneficiadas por sistemas de esgotamento sanitário (Braga et al., 1995).

Ao contrário do que se poderia imaginar, a extinção do BNH em 1986 e as transformações institucionais subsequentes, que levaram a gestão da política de saneamento para o Ministério do Planejamento e Orçamento, e seu financiamento para Caixa Econômica Federal (Nozaki, 2007), beneficiaram o setor. Isso porque, como expõe Braga (et al., 1995), a interrupção do uso dos recursos do FGTS para o setor de habitação abriu espaço para que estes fossem direcionados ao saneamento. Opção essa que perdurou por pouco tempo, eis que o saques dos recursos do fundo aumentaram durante o período, adotando o governo novas regulamentações para restringi-los, o que produziu reflexos no financiamento da política. De todo modo, os referidos autores apontam que, entre 1985-91, houve novos avanços no setor de abastecimento de água, que 
atingiu o montante de 82,5 milhões de usuários e no de esgotamento sanitário com 29,2 milhões de pessoas atendidas pelo sistema. A partir desse momento, há uma reorganização do papel desempenhado pelos estados na política pública. Isto é, estes deixam de desempenhar a função de executores de uma política centralizada, determinada pela União, para assumir uma condição de protagonismo na gestão e implementação do saneamento do país que perdurará nas décadas seguintes, definindo inclusive os rumos futuros das disputas envolvendo municipalistas e defensores das privatizações.

Em linhas gerais, é possível observar que, apesar dos evidentes avanços experimentados no curso da implementação do Planasa, verifica-se também inúmeros aspectos negativos associados ao programa - para além da dinâmica autoritária e centralizadora inerente ao regime militar, que teria contribuído pela viabilização do modelo. Ou seja, o foco na autossustentação financeira, com decisões tomadas tendo como parâmetro a rentabilidade do serviço, produziu como resultado uma política marcada pela exclusão, que privilegiou investimentos no abastecimento de água em detrimento do esgotamento sanitário, eis sua elevada rentabilidade e menor custo de investimento. Ademais, a decisão de concentrar recursos nas cidades mais populosas das regiões mais ricas do país (notadamente, Sudeste e Sul) ampliou ainda mais a desigualdade entre os diversos territórios nacionais.

Em associação às transformações relacionadas ao fim do regime militar e, em especial, verificadas a partir da reorganização federativa promovida a partir da Constituição Federal de 1988, observou-se em meados dos anos 1980 e 1990 uma progressiva desarticulação dos mecanismos institucionais e administrativos, representando a inviabilização da política nacional de saneamento desenhada pelo Planasa (Arretche, 1999). Ainda segundo a autora, dificilmente poderia se afirmar que, após a redemocratização e até o governo Itamar Franco, teriam sido adotadas medidas destinadas a reformular substantivamente a atuação do governo federal no setor. Pelo contrário, a despeito de certos avanços institucionais atinentes à gestão de recursos hídricos, concessões e permissões de serviços públicos, foram mantidos os mecanismos centralizados de distribuição do FGTS, cuja alocação passou a ser responsabilidade de uma burocracia suscetível a pressões e injunções de toda sorte. Essa complicada estrutura institucional ainda veio acompanhada de sucessivas trocas de ministros e demais funcionários do alto escalão governamental, prejudicando a implementação coordenada das políticas públicas.

Mesmo no primeiro governo Fernando Henrique Cardoso, Arretche (1999) sustenta que saneamento básico não era uma prioridade, tendo se verificado poucos avanços normativos, enquanto também se observava uma falta de coesão entre as inúmeras instituições que atuavam no setor - e.g., BNDES e Caixa. Em resumo, a autora percebe esse momento como uma "reforma sem reforma", ou seja, ainda que as transformações não estivessem sendo comandadas pelo governo federal, estas encontravam-se parcialmente condicionada às suas orientações para a política urbana. Isso significa dizer que, ante a lacuna deixada pela 
desestruturação institucional federal, os governos estaduais - em certos casos articulados com as gestões municipais - tiveram de elaborar soluções individualizadas envolvendo não só suas companhias de água e esgoto, mas a própria política pública.

A retração e a baixa organização institucional anteriormente observada no plano federal ganha novos contornos no segundo mandato de Fernando Henrique. Há um reposicionamento do governo sobre o tema que ocorre como contrapartida aos empréstimos obtidos junto ao Fundo Monetário Internacional (FMI) para auxiliar na contenção da crise financeira experimentada no período. Nesse caso, constitui-se o compromisso de privatização de diversos setores, dentre eles, energia, telecomunicações e saneamento. No que diz respeito ao último, as tentativas de implementação da referida agenda a partir da instituição de um marco regulatório federal fracassam face a robusta oposição articulada pela Frente Nacional pelo Saneamento Ambiental (FNSA) que, coordenada pela Federação Nacional dos Urbanitários/Central Única dos Trabalhadores (FNU/CUT), reuniu diversos atores sociais (Sousa \& Costa, 2011). Por outro lado, a Lei de Concessão de Serviços Públicos, sancionada em 1995, e o Programa de Modernização do Setor de Saneamento já seriam mais do que suficientes para fornecer elementos mínimos necessários ao início das privatizações.

Essa orientação de ampliação da iniciativa privada na política de saneamento foi significativamente encapada nos primeiros anos dos governos do Partido dos Trabalhadores (PT) que vislumbraram a condução de parcerias público-privadas como alternativa para a realização de investimentos no setor, inclusive com a aprovação de uma lei federal sobre o tema, em 2004 (Nozaki, 2007). Ocorre que, com a sanção da Política Nacional de Saneamento, em 2007, há uma reestruturação regulatória fundamental no setor. Isto é, ao invés de definir um desenho institucional único - tal qual ocorrera à época do Planasa - o novo regramento limitouse a estabelecer diretrizes para a articulação entre atores e funções, a despeito do arranjo institucional. Tal solução preconizou não só o novo ambiente institucional marcado pela presença dos municípios como entes federativos, mas também reconheceu sua heterogeneidade e, portanto, a necessidade de produzir soluções diferenciadas.

Mesmo diante dos incentivos à privatização do setor, houve uma substantiva retomada do investimento público mediante, por exemplo, a implementação do Programa de Aceleração do Crescimento (PAC), em suas diversas instâncias e versões. Esse movimento, que também vem acompanhado de recursos advindos de atores multilaterais, mantém-se constante, declinando apenas a partir da crise político-financeira de 2014. Diferentemente do caminho autoritário adotado no âmbito do Planasa, as principais medidas indutoras, que visavam estimular a adesão de estados e municípios à agenda federal, incluíam condicionar a contratação de prestadores de serviços e o acesso aos recursos da União ao desenvolvimento de medidas de planejamento e fortalecimento de instituições locais e regionais (Santos \& Vasques, 2015). 
A política pública na segunda década do século XXI

A importante reestruturação do cenário normativo, acompanhada de um contexto econômico pujante, contribuiu para a retomada dos investimentos no setor de saneamento. Com um novo marco legal aprovado em 2007, que tratou de questões como universalização da política, preservação ambiental e respeito às peculiaridades locais e regionais, há a tentativa de desenvolver estratégias alternativas para estimular o estreitamento das relações interfederativas, visando a implementação coordenada da política, notadamente, a partir de ferramentas de planejamento. Propõe uma maior transparência e acessibilidade para todos os atores envolvidos, em especial, no que tocante à estrutura das tarifas, bem como recoloca o papel da União como responsável pelo financiamento e gerenciamento do sistema (Dantas et al., 2012). Já sob esse novo paradigma, dados do Sistema Nacional de Informação sobre Saneamento (SNIS) apontam que saímos de 116,8 milhões de pessoas atendidas por abastecimento de água e 55 milhões por esgotamento sanitário em 2000 para, respectivamente, 147,7 e 82,7 milhões em 2010 e 167,7 milhões e 105,2 milhões em 2017.

Ademais, importante ressaltar que, em 2013, o Supremo Tribunal Federal (STF) proferiu decisão confirmando que a titularidade dos serviços de saneamento básico no país é municipal no caso daqueles territórios isolados. Na hipótese de cidades inseridas em regiões metropolitanas, a gestão deverá se dar de forma compartilhada, contudo, sem implicar em qualquer perda aos municípios - que estão compulsoriamente obrigados a participar dos arranjos metropolitanos, tal como fixado pelo STF. Tendo como referência a mencionada decisão, é sancionada a Lei do Estatuto da Metrópole, em 2015, visando contribuir para o desenvolvimento de um cenário institucional mais estável que favorecesse não só a organização da gestão regional dos aglomerados urbanos brasileiros, mas também a captação de recursos.

Ocorre que, em meio a trajetória de reajuste institucional experimentada no curso da primeira década do século XXI, a eclosão da crise político-financeira de 2014 implicou em uma nova retração dos investimentos em infraestrutura. Tem-se como hipótese que os sucessivos ataques, explicitados tanto por movimentos sociais, como por atores inseridos nas próprias instituições públicas às estruturas político-jurídicas consolidadas a partir da Constituição Federal de 1988 produziram instabilidades e rupturas que, até o presente momento, não se sabe se conduzirão a uma inflexão do modelo ou a sua desestruturação. De todo modo, o que vem se observando no âmbito do saneamento é uma tentativa de certos atores de atuar em meio a essa instabilidade a fim de reorientar a política pública. As recentes propostas de alteração do modelo regulatório sancionado em 2007 vão nessa linha, ou seja, visam conferir uma melhor e maior capacidade de incidência à iniciativa privada no setor. Assim, a partir das informações produzidas pelo SNIS, pretende-se construir um diagnóstico da atuação pública (estadual e municipal) e privada e, a partir do histórico introduzido na seção anterior, desenvolver uma interpretação crítica das informações trabalhadas a fim de melhor avaliar as 
propostas de mudança recentemente apresentadas, bem como a posição dos atores diretamente envolvidos na disputa.

Para conduzir a análise proposta, foram utilizados dados produzidos pelo SNIS entre 2011 a 2017 (último ano disponível) referentes aos serviços de abastecimento de água e esgotamento sanitário, em que foram observados tanto informações sobre população (i.e., número de pessoas beneficiadas), como indicadores de atendimento (i.e., abastecimento de água - IN055; esgotamento sanitário - IN056) desenvolvidos pelo próprio SNIS. Tais elementos foram organizados considerando a natureza jurídica do prestador de serviço (i.e., privado ou público), e, no caso desse último, dividiu-se também entre estadual e municipal. Por último, além da conjugação dos dados a nível nacional, foram conduzidas observações a partir das regiões políticas.

Em linhas gerais, é possível observar um tímido crescimento da iniciativa privada tanto no setor de abastecimento de água como no esgotamento sanitário. No atual contexto, o decréscimo de participação municipal parece definir os espaços de incidência dos grupos privados. No período estudado, há uma estagnação relativa na cobertura do serviço de água, enquanto que se observa uma expansão dos sistemas de esgotamento - uma explicitação da orientação de política pública adotada nos últimos anos, ou seja, de ampliação das redes de existentes. Interessante notar que esse crescimento se dá - no setor público - na mesma proporção para as administrações municipais e estaduais, permitindo aventar a hipótese de que a distribuição dos recursos federais teria se dado com uma maior capilaridade. Por último, observou-se uma maior concentração da inciativa privada nas regiões Sudeste, Centro-Oeste e Norte, enquanto que os maiores montantes de participação municipal se inscrevem nas regiões Sudeste e Sul, provavelmente em virtude de melhor configuração institucional combinada com maior autonomia orçamentária.

Em relação à Figura 1, que explicita a participação percentual no universo dos serviços de água e esgoto prestados a nível nacional entre setor público e privado no período estudado, observa-se um crescimento da atuação de particulares. Esse movimento se dá tanto para o setor de abastecimento de água como de esgotamento sanitário. No caso do primeiro, evidencia-se um acréscimo de 1,3\% entre 2011-2017, com destaque até o ano de 2015. Sobre o segundo, há ainda um maior incremento na participação que, até o final do período, atinge uma diferença de 3\%, também com acentuado desenvolvimento até 2015, cuja dinâmica pode estar relacionada à eclosão da crise político-financeira no ano anterior. A hegemonia do setor público no saneamento reforça a percepção de que há um amplo campo a ser explorado a partir de parcerias com a iniciativa privada. 
Figura 1. Participação percentual nos serviços de água $(A G 001)^{1}$ e esgoto (ES001) em âmbito nacional entre setor público e iniciativa privada por ano (2011-2017). Fonte: elaboração própria a partir dos dados do SNIS (2011-2017)

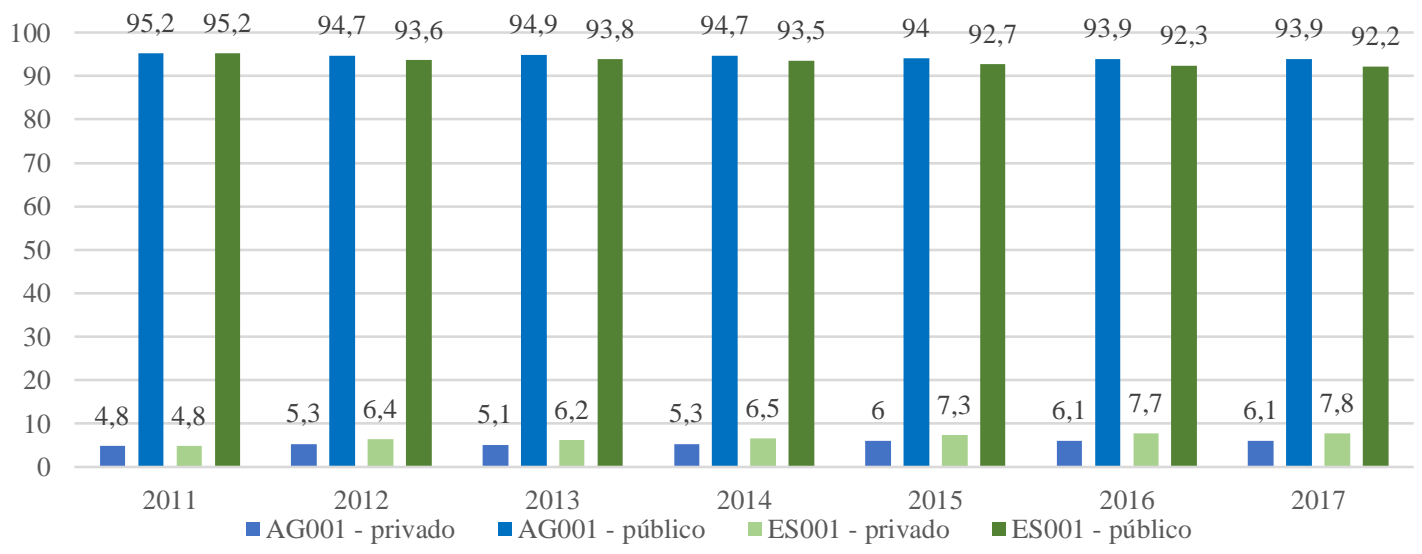

A partir da Figura 2 é possível destrinchar a participação percentual no universo de atuação do setor público no período estudado, dividindo entre a gestão realizada pelos municípios ou por governo estaduais, seja através da administração direta, autarquia, empresa pública ou sociedade de economia mista. Os dados apontam para uma baixa variação da participação tanto no abastecimento de água como no esgotamento sanitário. Interessante observar que, no caso do primeiro, há uma redução da participação municipal de 0,5\%, entre 2011-2017, enquanto no segundo, o valor mantém-se o mesmo. Essa baixa flutuação, mas que segue indicando um declínio da atuação municipal, indica a hipótese de que a expansão da iniciativa privada pode estar sendo conduzida a partir da sua incidência nos sistemas locais de saneamento, em detrimento dos mecanismos regionais, cujo risco e investimento são muito superiores.

Figura 2. Participação percentual nos serviços de água (AG001) e esgoto (ES001) em âmbito nacional entre gestão municipal e estadual por ano (2011-2017). Fonte: elaboração própria a partir dos dados do SNIS (2011-2017).

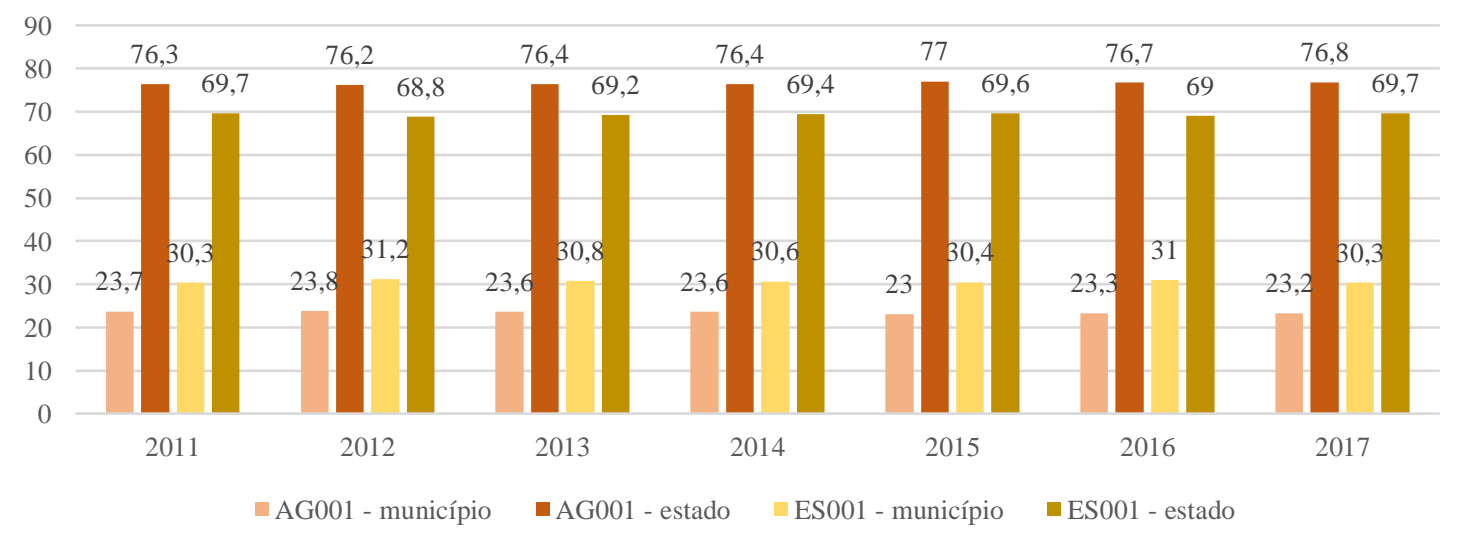

${ }^{1}$ AG001 e ES001 fazem referência às categorias de informação retiradas da base de dados do SNIS para elaboração dos gráficos 
No caso da Figura 3, observa-se o percentual de implementação dos serviços de água e esgoto a nível nacional, divididos entre atuação pública e privada no período analisado ${ }^{2}$. Interessante notar que os grandes avanços identificados nas décadas anteriores no âmbito do abastecimento de água encontram-se neste momento bem mais limitados. Ainda que no setor público se verifique uma tímida evolução que não só ultrapassa o crescimento população, mas também imprime algum incremento, é na iniciativa privada que se identifica uma maior expansão. Estima-se que tais resultados podem estar associados a obrigações assumidas pelos gestores privados no âmbito de contratações realizadas em momentos anteriores. E, no caso do declínio nos últimos dois anos, avalia-se que tal dinâmica pode estar implicada nos desdobramentos da crise financeira, mas também pode estar relacionada ao aumento da participação privada no abastecimento de água verificado a partir de 2015, na Figura 1. Os avanços mais expressivos se dão no setor de esgotamento sanitário tanto para gestões públicas - i.e., um avanço de 4,4\% ao final do período - como privadas - i.e., 7,2\% entre 20112017. Esse resultado mostra-se esse em linha com uma orientação de política pública que privilegiou a expansão do sistema de atendimento. Ou seja, uma característica dos governos do PT no caso da implementação do PAC e, ainda, de eventuais transferências para iniciativa privada.

Figura 3. Implementação percentual dos serviços de água (IN055) ${ }^{3}$ e esgoto (IN056) em âmbito nacional entre setor público e iniciativa privada por ano (2011-2017). Fonte: elaboração própria a partir dos dados do SNIS (2011-2017)

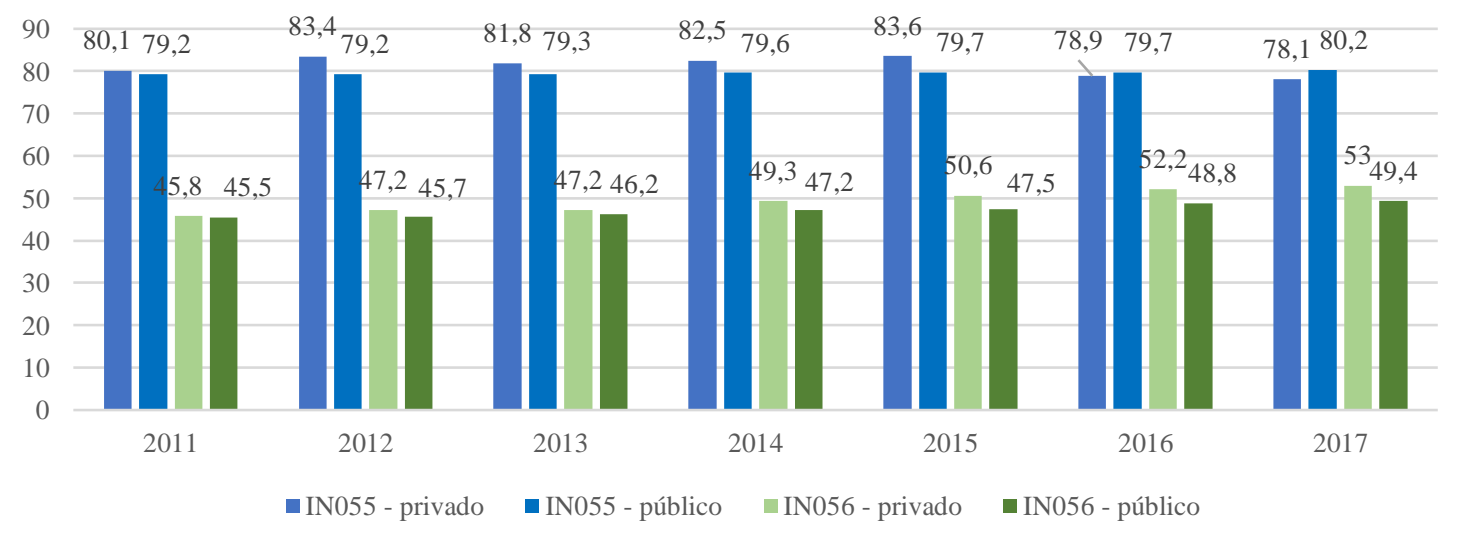

Já a Figura 4 explicita a relação município-estado na implementação dos setores de abastecimento de água e esgotamento sanitário em âmbito nacional no período estudado. Os dados mostram que, mesmo considerando as variações no setor de água gerido pelos municípios, estas não são suficientes para impactar

\footnotetext{
2 Importante ressaltar que foi identificada uma divergência na observação dos indicadores construídos pelo SNIS. Ou seja, como algumas concessões foram realizadas por bairros (e.g., zona oeste do município Rio de Janeiro) e as informações coletadas limitamse ao nível municipal, detectou-se duplicidade no cômputo de certas variáveis - como é o caso da população total beneficiada - que precisou ser ajustado para que os indicadores fossem adequadamente manejados.

3 IN055 e IN056 fazem referência aos indicadores retirados da base de dados do SNIS para elaboração dos gráficos. Seu resultado é extraído da equação população atendida pelo serviço (AG001, no caso de água, ou ES001, para esgotamento sanitário) sobre população total (G12A).
} 
os resultados da administração pública, como descritos na Figura 3. E tais informações potencialmente indicam- a partir das referidas flutuações - uma dificuldade maior das gestões municipais de avançar na ampliação e/ou manutenção dos sistemas de abastecimento existentes. Esse resultado pode estar relacionado à concentração dos recursos públicos disponibilizados para o setor de esgotamento sanitário. Importante destacar que, nesse caso, tanto municípios como estados apresentaram variações no período muito parecidas, isto é, 3,7\% para os primeiros e 3,9\% para os segundos. Esses números podem estar relacionados a uma maior extensão do acesso aos recursos públicos, atingindo mesmo aqueles que não estão integrados aos arranjos institucionais regionais. $\mathrm{E}$, nesse caso, que os próprios municípios tiveram êxito em captar recursos junto ao governo federal, atendendo às demandas de acesso aos investimentos por ele formuladas. Surge, nesse contexto, a necessidade de avaliar a nível municipal como essa expansão dos sistemas locais ocorreu. Isto é, se predominantemente em municípios mais populosos e melhor estruturados institucionalmente, ou se incluiu cidades menores e menos integradas - reafirmando a hipótese de que teria havido uma maior capilarização dos recursos federais.

Figura 4. Implementação percentual dos serviços de água (IN055) e esgoto (IN056) em âmbito nacional entre gestão municipal e estadual por ano (2011-2017). Fonte: elaboração própria a partir dos dados do SNIS (2011-2017)

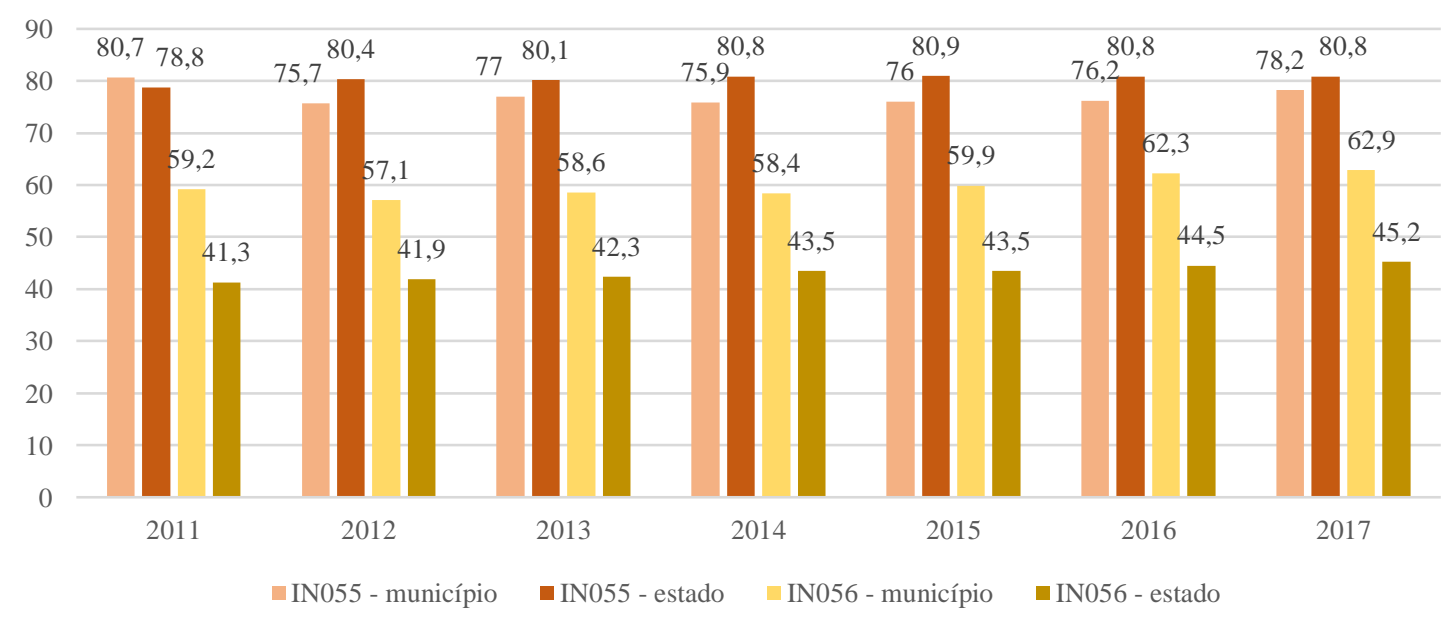

Os dados introduzidos pela Figura 5 propõem uma mudança do eixo analítico. Isso porque, dividiu em regiões a participação pública e privada nos setores de água e esgoto para 2017, último ano disponível pelo SNIS. A partir desse deslocamento, verifica-se que, ainda que haja alguma presença da iniciativa privada no Sul do país, são as regiões Sudeste, Centro-Oeste e Norte de que concentram a maior participação, ficando o Nordeste praticamente excluído dessa dinâmica. No caso da primeira, o Estado do Rio de Janeiro concentra mais da metade da população potencialmente atendida, seguido por São Paulo. Já na região Centro-Oeste, Mato Grosso agrega dois terços do resultado, ficando o restante identificado no Mato Grosso do Sul. Por 
último, é possível destacar os Estados do Amazonas e do Tocantins como aqueles em que maior se constata a participação privada na prestação dos serviços. Em regra, observa-se uma predominância da atuação de atores particulares no setor de abastecimento de água. A exceção identificada pelo Sudeste se dá em virtude da peculiar privatização do sistema de esgotamento sanitário na zona oeste do Município do Rio de Janeiro que não veio acompanhada do fornecimento de água - serviço este que continuou sendo prestado pela Companhia Estadual de Águas e Esgotos (CEDAE).

Figura 5. Participação (em número de pessoas) nos serviços de água (AG001) e esgoto (ES001) em âmbito regional entre setor público e iniciativa privada no ano de 2017. Fonte: elaboração própria a partir dos dados do SNIS (2017)

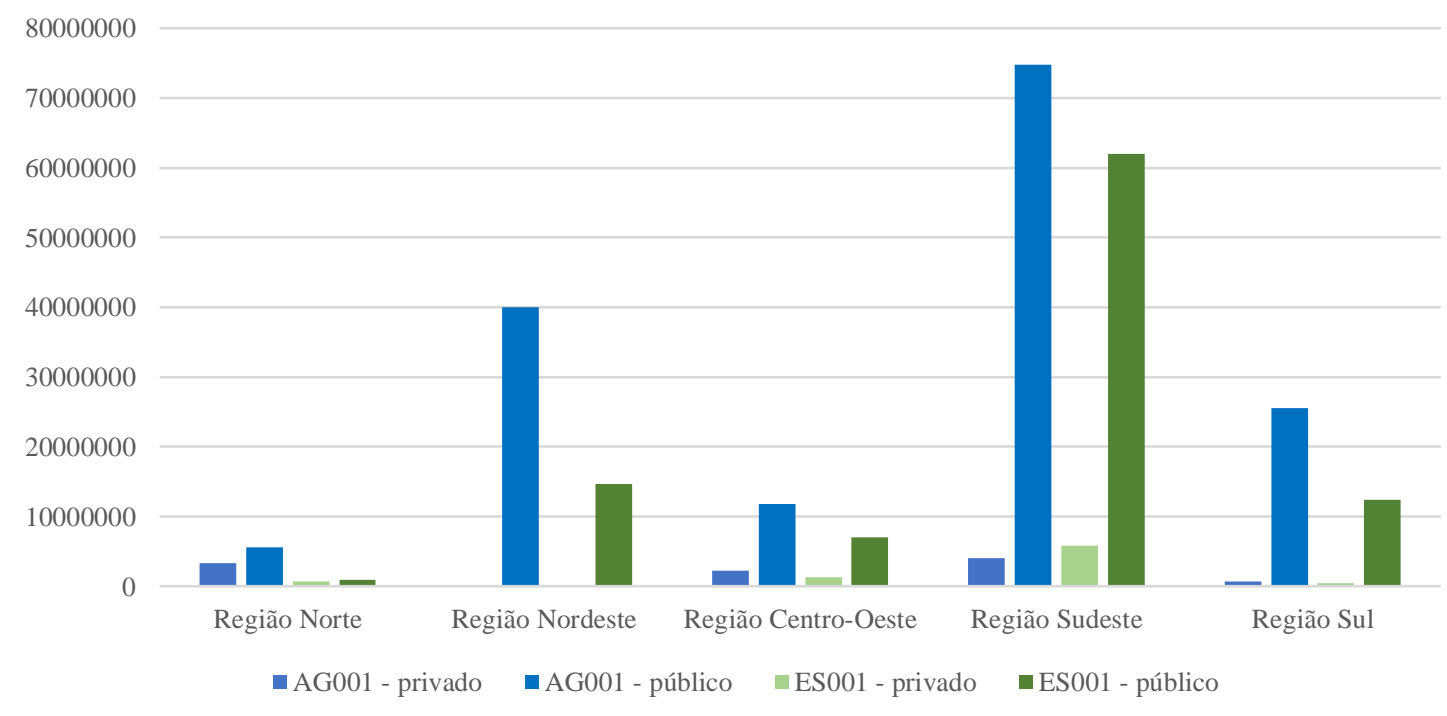

A Figura 6, também sob a perspectiva regional, avalia a participação de municípios e estados, em número de pessoas atendidas, na gestão de água e esgoto em 2017. É possível verificar de imediato a concentração da atuação municipal nas regiões Sudeste, na qual o peso em relação à gestão estadual ultrapassa a metade no setor de esgotamento sanitário, e no Sul em que a participação também se coloca de modo relevante. Esses números provavelmente encontram-se relacionados tanto a uma institucionalidade melhor constituída e, em especial, a uma maior autonomia orçamentária, permitindo a esses territórios conduzir os investimentos, ou assumir contrapartidas exigidas. Norte e Centro-Oeste lideram a concentração da gestão estadual, reforçando a afirmação anterior e, no caso da primeira região, o resultado é agravado pelos altos custos de implantação, haja vista as condições naturais e as características das ocupações - o que, em regra, demandaria o desenvolvimento de soluções em água e esgoto alternativas em relação aos aglomerados urbanos tradicionais. Cabe observar, ainda, o resultado da região Nordeste que, apesar da larga abrangência de atuação das companhias estaduais, se destacou pela elevada presença de gestões municipais. 
Figura 6. Participação (em número de pessoas) nos serviços de água (AG001) e esgoto (ES001) em âmbito regional entre gestão municipal e estadual no ano de 2017. Fonte: elaboração própria a partir dos dados do SNIS (2017)

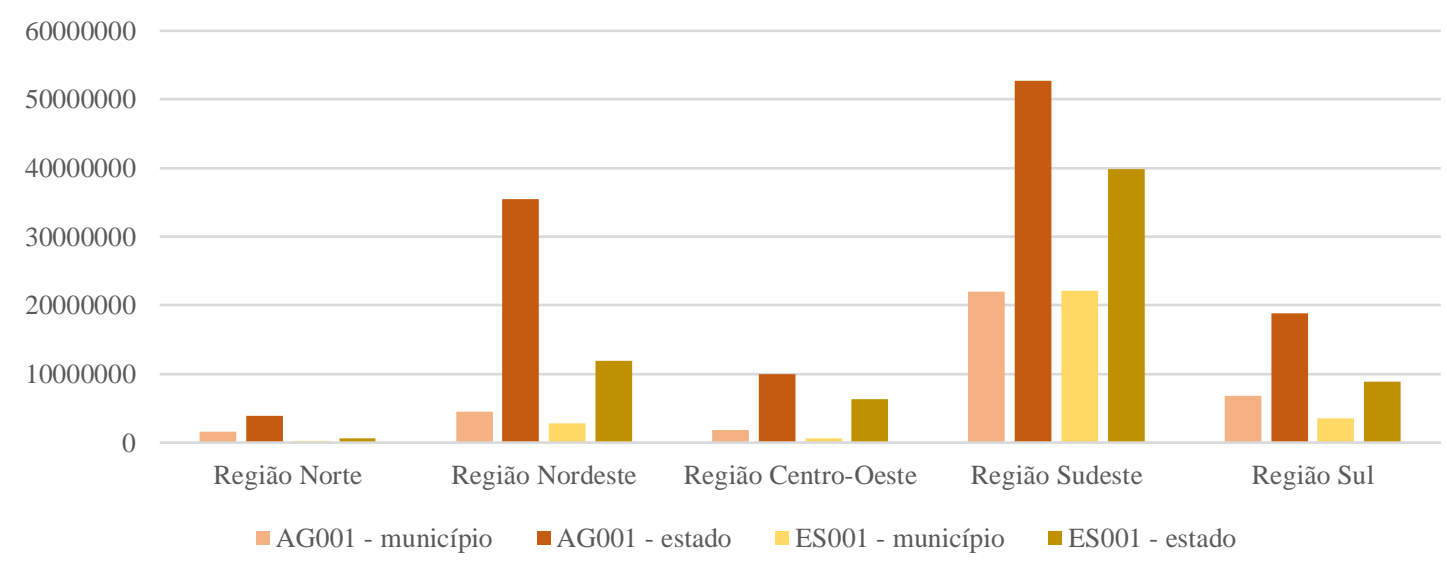

Por fim, a análise dos dados trabalhados explicita que, até a segunda década do século XXI, o setor vem resistindo à uma integração substantiva do setor privado. Por outro lado, a manutenção hegemônica das companhias estaduais evidencia que, em regra, a gestão coordenada do saneamento ainda depende de uma institucionalidade centralizadora, restando rarefeitos os traços inerentes ao que o STF definiu como gestão compartilhada - mesmo considerando a existência de consórcios e convênios públicos.

As novas propostas a partir da trajetória regulatória do setor

Antes de tratar das questões atinentes às propostas atuais de modificação do marco regulatório vigente, é preciso voltar e observar, ainda que de forma sucinta, algumas etapas anteriores dessa trajetória. Para tanto, são trabalhados elementos contextuais, mas também relacionados às primeiras propostas de constituição de um marco normativo para o saneamento após a promulgação da Constituição Federal de 1988. Importante reiterar que, com a derrocada do Planasa, passava a ser necessário repensar não só as instituições ligadas à política pública, mas também o seu conceito. Segundo Bier (et al., 1988), havia um consenso sobre a necessidade de ampliar a definição de saneamento - indo para além de água e esgotamento - para incluir também limpeza urbana, drenagem, gestão de mananciais e resíduos sólidos, bem como a necessidade de articular as ações entre outras políticas, em especial, saúde pública. Ademais, a redemocratização contribuiu para impulsionar outras demandas como ampliação do controle popular, mais transparência, descentralização do planejamento e execução das políticas públicas etc. E, por último, parecia estar claro que a utilização das companhias estaduais como instrumento de política econômica e a necessidade de o sistema se autofinanciar a qualquer custo eram pontos de deveriam ser evitados. Restava, no entanto, responder como se daria essa 
reestruturação da política pública ante ao alto estoque de dívida pública e a consequente baixa capacidade de investimento para manutenção e ampliação dos sistemas de abastecimento de água e esgotamento sanitário.

Dentre as inúmeras propostas, e na ausência de um marco regulatório nacional, Arretche (1999) identificava duas grandes estratégias de mudança. A primeira privilegiava o fortalecimento das companhias estaduais, e teria sido o caso de São Paulo e do Paraná, que investiram em novos modelos de gestão, ampliação da eficiência, área de atuação e taxas de cobertura, diversificação das fontes de recursos, e abriram o capital da empresa. A segunda propunha o desmantelamento das referidas companhias, seja pela via da municipalização, seja por meio de privatizações. No caso da transferência para os municípios da gestão da política, a autora aponta o processo verificado no Estado do Mato Grosso, que devolveu as funções de gestão dos sistemas de saneamento básico. E sobre as privatizações, indica o processo relacionado à CEDAE, mas que, até hoje, não foi efetivamente concretizado.

Dentre as várias propostas apresentadas, o que se observou no âmbito da trajetória de disputa normativa foi uma oscilação entre os campos público e privado, em regra, envolvendo de um lado propostas de reformas institucionais e tributárias e, do outro, a privatização dos serviços de utilidade pública. A primeira formalmente apresentada no legislativo federal foi o Projeto de Lei n. 53/1991, pela Deputada Irma Passoni (PT-SP), que instituía a Política Nacional de Saneamento (Borja \& Moraes, 2006). O projeto propunha assegurar os benefícios da salubridade ambiental, por meio da atuação articulada entre União, Estados, Distrito Federal e Municípios, respeitando sua autonomia político-administrativa, e em harmonia com outras políticas públicas (e.g., saúde pública, desenvolvimento urbano, recursos hídricos, meio ambiente, o plano plurianual e a lei de diretrizes orçamentárias). Além da definição ampliada de saneamento, passou a trata-lo como um direito social, assegurado universalmente, a partir de mecanismos de gestão descentralizados, incluída a participação da comunidade. Interessante destacar que, ainda que o projeto tenha reforçado a titularidade municipal sobre a gestão da política, também definiu os limites da atuação estadual sobre o tema. Isto é, circunscreveu a competência dos estados às tarefas de organização, planejamento e execução das funções de interesse comum nas regiões metropolitanas, aglomerações urbanas e microrregiões. Nesse sistema, caberia à União coordenar e estimular a implementação da política, apoiar os Estados no suporte aos seus municípios, e ajudar diretamente as municipalidades, respeitados os planos estaduais.

O PL n. 53/1991 também previu a possibilidade de constituir organizações político-administrativas diferenciadas para atender as distintas realidades brasileiras, bem como valorizou articulações interinstitucionais, e soluções intermunicipais ou inter-regionais. Definiu a criação de novas instituições, mecanismos de diagnóstico, controle e financiamento, como o Plano Quinquenal Nacional e Saneamento, o Conselho, e o Fundo para política pública. Entretanto, como destacam Turolla \& Ohira (2007), apesar de o projeto haver sido discutido e aprovado pelo Congresso Nacional ainda no governo Collor, sua apreciação pelo 
Executivo ocorre somente na administração seguinte, de Fernando Henrique Cardoso, que o veta integralmente logo após sua posse em 1995. Borja \& Moraes (2006) ressaltam que o PL havia sido produto de discussões e negociações entre diversos atores sociais. Para os autores, o veto constituiu um dos primeiros passos em direção à concretização da diretriz política que o governo adotaria nos anos seguintes, isto é, a privatização dos serviços de saneamento. A etapa seguinte foi a apresentação, ainda em 1995, da Política Nacional de Saneamento pelo governo de Fernando Henrique. O documento explicitava a orientação de modernização e flexibilização na prestação dos serviços, em especial, a partir de privatizações. Adicionalmente, adota como prioridade o desenvolvimento de um marco regulatório nacional, em consonância às contrapartidas pactuadas com o Banco Mundial e FMI, anteriormente mencionadas.

No ano seguinte, em substituição ao projeto vetado, o senador José Serra (PSDB-SP) apresenta uma nova proposta ao Congresso, sob o n. 266/1996 que, por sua vez, foi apensada ao PL n. 500/1999, do senador Paulo Hartung (sem partido-ES). Ambos os projetos tramitaram de forma tímida até o final da legislatura respectiva e, não tendo sido aprovados, foram arquivados. De qualquer modo, em resposta às tentativas de viabilizar a privatização do setor, foi articulada uma frente de resistência composta por movimentos sindicais, sociais, comunidades profissionais etc., intitulada Frente Nacional pelo Saneamento Ambiental (FNSA) que, a partir de uma argumentação jurídica, contribuiu para que os referidos projetos não prosperassem. Importante notar que os principais setores que compunham a FNSA eram as entidades sindicais, os profissionais e, em especial, os municipalistas. A articulação chegou inclusive a produzir o projeto de lei n. 2.763/2000 apresentado pelos deputados Sérgio Novaes (PSB-CE) e Maria do Carmo Lara (PT-MG) (Sousa \& Costa, 2011). É nesse momento também (i.e., em 1998) que são ajuizadas as Ações Diretas de Inconstitucionalidade no STF questionando a titularidade dos serviços de saneamento básico.

Como alternativa aos avanços limitados das propostas anteriores, em paralelo, o próprio Executivo apresenta, em 2001, na Câmara dos Deputados sua proposta legislativa visando instituir diretrizes nacionais para o saneamento básico. Tal como reitera Turolla \& Ohira (2007), ambos os projetos tinham como um de seus principais objetivos facilitar a privatização dos serviços de saneamento. Nessa nova versão, registrada sob o n. 4.147/2001 e apensada ao PL 2.763/2000, retoma-se uma conceituação estrita sobre saneamento, mas, por outro lado, são propostas definições objetivas sobre interesse local e comum, bem como sobre gestão associada. Atrela-se a política pública à bacia hidrográfica, à obrigação de universalização, prevendo também a necessidade de articulação com outras políticas. A necessidade de adaptação às peculiaridades regionais, participação popular e desenvolvimento e pesquisa aparecem de forma superficial. Na linha do que fora mencionado, o PL tinha como sua espinha dorsal um conjunto de regras para a concessão dos serviços, visando ampliar a participação da iniciativa privada. 
Entretanto, diferentemente do que previa, o governo fracassou na sua tentativa de aprovar um marco regulatório nacional. E, novamente, a oposição organizada ao projeto foi articulada pela FNSA. Como apresentam Sousa \& Costa (2011), apesar da formação de uma agenda comum contra as privatizações, haviam interesses inconciliáveis no interior da Frente, em especial, no que diz respeito à titularidade dos serviços, que colocava municipalistas - e.g., Federação de Órgãos para Assistência Social e Educacional (FASE) e a Associação Nacional dos Serviços Municipais de Saneamento (ASSEMAE) - e estadualistas - e.g., Fórum Nacional de Secretários Estaduais de Saneamento e da Associação das Empresas Estaduais de Saneamento Básico (AESBE) - em contraposição. Exatamente por conta das incompatibilidades, as coalizões formadas pela FNSA eram instáveis e variaram durante o processo de oposição ao PL. Ademais, o próprio setor privado também encontrava divergências em seu interior, eis que para os grandes grupos internacionais a estadualização era um ponto importante, enquanto que, para as companhias brasileiras a municipalização era mais atraente, haja vista sua menor capacidade de risco e investimento.

Nesse contexto, por conta de o PL 4.147/2000 se caracterizar por privilegiar uma estrutura estadualista, o projeto conseguiu o apoio dos governadores, afastando a Associação Brasileira de Engenharia Sanitária e Ambiental (ABES) da FNSA. Dessa forma, ainda que a estratégia principal da Frente fosse mobilizar partidos de oposição, a opção governista de privilegiar a gestão estadual do saneamento acabou por produzir rupturas em sua base aliada que passou a se opor ao projeto de lei. A partir desse comportamento, a FNSA acaba por reorganizar sua atuação, ampliando seus laços com outros movimentos sociais e também com os partidos até então aliados ao governo. Sousa \& Costa (2011) indicam que esse movimento teria sido feito não só a partir de trabalhadores e usuários, mas, principalmente, por meio da conscientização dos executivos e legislativos municipais. O objetivo era alertar para os potenciais prejuízos associados à transferência da titularidade para os Estados. Como resultado, conseguiu agregar o apoio da Associação dos Municípios Brasileiros (AMB), da Confederação Brasileira dos Municípios (CBM), e da Frente Nacional de Prefeitos (FNP). Estes pressionaram deputados que, dependentes das bases locais, aderiram ao municipalismo.

As mobilizações contrárias ao Projeto conseguiram não só retirar a urgência, mas também que fosse elaborado um substituto. Entretanto, este sequer chegou a ir a plenário. Por não contemplar as demandas do Executivo, tampouco aquelas privilegiadas pela FNSA, a nova proposta foi abandonada. Sousa \& Costa (2011) reiteram que o novo texto inclusive teria desagradado setores do próprio PSDB, do Fórum Nacional de Secretários Estaduais de Saneamento e da Associação das Empresas Estaduais de Saneamento Básico (AESBE). Isso porque, além de não ter contemplado os interesses municipalistas, também não satisfez os estadualistas, e retirou a segurança jurídica alegadamente necessária à condução das privatizações. Por outro lado, a impossibilidade de gerar um consenso mais amplo no interior da FNSA também inviabilizou a apresentação de novas propostas. Esse cenário se modifica apenas após o início do governo Lula em 2003, quando, segundo 
Vargas \& Lima (2004), o então Ministro das Cidades, Olívio Dutra, determinou a retirada do PL n. 4.147/2000 do Congresso e uma nova proposta passou a ser desenvolvida.

Em um texto mais recente, Sousa \& Costa (2016) sustentam que os atores sociais contrários à privatização serviram de base eleitoral para a eleição de Lula, e dirigentes de suas principais instituições, como a FNSA, foram alocados em posições estratégicas no interior do governo federal. Havia a expectativa que, a partir desse movimento, seria possível modernizar o setor e aprovar um novo marco regulatório. Em maio de 2005, após 11 audiências públicas, consulta pública pela internet, discussão em reuniões regionais e nacional realizadas com esse objetivo, e apreciação e aprovação pelos Conselho das Cidades e Conselho Nacional de Saúde (Borja \& Moraes, 2006), o executivo federal encaminha ao Congresso o PL n. 5.296/2005, que institui a Política Nacional de Saneamento Básico. Dentre os instrumentos introduzidos e mantidos em sua versão final destaca-se uma visão mais integrada de saneamento, novos mecanismos de gestão e planejamento, subordinação dos prestadores de serviços a agências reguladoras etc.

O PL n. 5.296/2005 foi objeto de centenas de emendas, em sua maioria, voltadas para atender interesses estadualistas. Dentre os temas mais debatidos encontram-se a titularidade dos serviços, a instituição do Sistema Nacional de Saneamento (Sisnasa) - visando romper com o monopólio dos estados sobre o saneamento -, a previsão de fundos federativos para a universalização dos serviços - objetivando democratizar o processo decisório sobre a alocação dos recursos - e a instituição de órgãos colegiados com natureza deliberativa - conferindo efetivo controle social sobre o setor. A favor do projeto se posicionaram a FNSA - no entanto, sem o apoio das entidades estaduais -, outros movimentos sociais, associações de prefeitos e pequenas empresas privadas. Do outro lado, a posição dos governadores estaduais foi sustentada por grandes companhias inseridas na cadeia produtiva do setor. A impossibilidade de um consenso em um primeiro momento fez com que um novo projeto fosse apresentado no Senado em favor dos interesses estadualistas. Segundo Sousa \& Costa (2016), a rápida tramitação e aprovação do referido texto e a ameaça de uma derrota, ainda mais preocupante frente às tensões e incertezas trazidas pelo pleito eleitoral seguinte, demandou um reposicionamento dos municipalistas que tiveram de ceder em diversos pontos a fim de viabilizar de um acordo. Dentre eles, é possível destacar o abandono da discussão sobre a titularidade - eis que ainda se encontrava sob discussão judicial no STF -, da criação do Sisnasa, dos fundos setoriais e dos conselhos deliberativos - que não só se tornaram facultativos, mas também de natureza consultiva. Assim, foi aprovado o PL e sancionado como lei sob o n. 11.445/2007. A despeito dos avanços na política, introduzidos com a aprovação de um marco regulatório nacional, e tornados possíveis a partir da estratégia conciliadora adotada no governo Lula, a vitória dos interesses estadualistas e, nesse sentido, da hegemonia das estruturas centralizadoras legadas pelo Planasa, restou evidente. 
A crise de político-financeira que emerge em 2014, e que tem como um de seus pontos principais o impeachment de Dilma Rousseff em 2016 - contribuindo significativamente para a produção de novas rupturas institucionais -, constituiu uma nova janela de oportunidade política para a retomada das discussões sobre a privatização no setor de saneamento. Nesse contexto, em julho de 2018, o executivo federal, sob o comando de Michel Temer, edita a MP 844. Em linhas gerais, a nova norma propunha concentrar na Agência Nacional de Águas (ANA) a competência para fixação de tarifas, modificar as regras envolvendo contratos de programa - que passariam a ser submetidos a processos licitatórios -, alterar a titularidade municipal, bem como o subsídio cruzado e a lógica dos ganhos de escala. A decisão de edição da MP, que parece ter sido realizada sem o diálogo com diversos dos atores do setor, promoveu uma nova rearticulação social, tal como aquela experimentada durante o governo Fernando Henrique. Isto é, as disputas entre estadualistas e municipalistas novamente são colocadas de lado frente à ameaça de privatização do setor. Dessa forma, grupos como a Associação Brasileira de Municípios (ABM), a Associação Brasileira de Agências de Regulação (ABAR) - que, posteriormente, muda de posição -, a ABES, AESBE, ASSEMAE, FNU, FNP, FNSA e Federação Nacional de Engenheiros (FNE) voltam a se reunir defendendo a inconstitucionalidade da medida provisória. Para eles havia um grande risco de aumento das tarifas e água e esgoto, comprometimento das metas de universalização, bem como a desestruturação do setor, agravando a desigualdade.

Frente à impossibilidade de se chegar a um acordo, em novembro de 2018, a MP 844 perde sua vigência, sem ser apreciada pelos plenários da Câmara e do Senado. Entretanto, de forma inesperada, inclusive para os setores apoiadores da MP, que incluíam a Associação Brasileira das Concessionárias Privadas de Serviços Públicos de Água e Esgoto (ABCON), a Associação Brasileira da Infraestrutura e Indústrias de Base (ABDIB), a Confederação Nacional da Indústria (CNI), o Instituto Trata Brasil etc., a MP é "reeditada" sob o n. 868, ainda em 2018, no final do governo Temer. Novamente, sem discussão ampla com a sociedade civil, governadores, prefeitos e demais atores sociais, o executivo federal tenta manter a proposta de privatização do setor introduzida pela MP anterior, transferindo para a legislatura seguinte a atribuição de votar a MP 868. Para os grupos apoiadores, a regra traria oportunidade para novos investimentos por meio da participação privada, ampliando a possibilidade de promover a universalização, eis que - sob seu discurso - os déficits vêm se mostrando inatingíveis ante as limitações de uso dos recursos públicos para tal finalidade, em especial, após a crise de 2014. Adicionalmente, tal medida representaria uma forma de contribuir para o equacionamento fiscal dos estados. Entretanto, mesmo com a retração de parte da oposição estadual - capitaneada pelo governador de São Paulo, João Doria (PSDB-SP) -, os atritos entre o governo Bolsonaro e o Congresso, e a impossibilidade de se chegar a um consenso, impediram a formulação de um acordo a tempo para votar a MP 868 e ajustou-se que as alterações no marco regulatório seriam realizadas mediante a apresentação de um novo projeto de lei. 
O texto do projeto de lei de conversão da MP 868 é reproduzido e apresentado de forma autônoma pelo Senador Tasso Jereissati (PSDB-CE), em junho de 2019, logo após o vencimento da Medida Provisória, sob o n. 3.261/2019. No mesmo mês, o PL é aprovado e a versão final do texto, ainda mais radical do que a MP 868 - chegando a vedar os contratos de programa -, é encaminhada para apreciação pela Câmara dos Deputados. Esta, por sua vez, passa a tramitar o PL sob regime prioritário, e constitui uma Comissão Especial para apreciar o texto enviado pelo Senado ${ }^{4}$. Tal como na avaliação das MPs, há um retorno dos atores sociais anteriormente envolvidos que retomam os processos de mobilização contra (FNU, ASSEAME, FNSA, ABES, AESBE, FNP, $A B M)$ e a favor (ABCON e ABDIB), agora, do Projeto de Lei. É possível nesse momento identificar a participação de novos atores, como o Observatório Nacional dos Direitos à Água e ao Saneamento (ONDAS), constituído em 2018 por entidades sociais, sindicais e acadêmicas, o Consórcio Nordeste, a Confederação Nacional de Prefeitos, organizações de juristas, membros da academia e etc.

A despeito do célere processo no Senado, a forma como o projeto vem caminhando na Câmara aponta para um processo legislativo mais sinuoso. Ademais, não vem sendo possível identificar relevante demonstração de preocupação com o tema por parte do novo executivo federal, ainda que o legislativo tenha sinalizado sua aprovação como prioritária. De todo modo, importante considerar que, ante as dificuldades de o governo Bolsonaro de produzir articulações eficientes junto ao Congresso, orientando as prioridades da pauta nacional, o que tem se verificado é que esse protagonismo vem sendo assumido pelo próprio legislativo, que está coordenando de forma proativa o ritmo e o conteúdo das votações de grandes temas, como a reforma da previdência, tributária, federativa etc. Resta saber, ao final dessas pautas defendidas como prioritárias, qual será a posição tanto do executivo como do legislativo frente à alteração do marco regulatório do saneamento. Isto é, ainda que o PL esteja efetivamente tramitando na Câmara, é evidente que a necessidade de formação de consensos entre os diversos atores sociais envolvidos remanesce indispensável para qualquer mudança significativa, demandando acordos e concessões. Tal afirmação é reiterada haja vista a resistência apresentada mesmo em um cenário de ruptura - ou, na melhor das hipóteses, de instabilidade institucional -, que impediu as tentativas de alterar a legislação de forma unilateral e sem diálogo (vide MPs 844 e 868). Assim, mesmo com a flexibilização de certos apoios estaduais, como do governador de São Paulo - cuja decisão pode estar orientada para os próximos processos eleitorais -, remanesce sólida a base política e social contrária à privatização, ainda que parte desse grupo esteja interessada nos recursos privados.

\section{CONSIDERAÇÕES FINAIS}

\footnotetext{
${ }^{4}$ Até outubro de 2019, a Comissão Especial já havia elaborado um substitutivo ao texto apresentado pelo Senado que ainda aguardava aprovação final de todos os seus membros.
} 
A constituição do Planasa durante o regime militar marca o início de uma política nacional para o saneamento que estruturou as bases do sistema atualmente vigente. Ainda que diversos elementos tenham sido abandonados, entre eles, os mecanismos autoritários empregados para manter o sistema centralizado, a derrocada do Planasa produziu um deslocamento do controle hegemônico da política pública da União em direção aos estados. Antes tidos como meros braços executores do governo federal, os governos estaduais, a partir das companhias de saneamento, tomam para si o protagonismo perdido pela União em virtude, primeiramente, da crise financeira e, em seguida, em decorrência das reestruturações institucionais produzidas a partir do processo de redemocratização. Sua posição de controle é tão evidente que, com o apoio de outros atores sociais, foi capaz de manter seu protagonismo ante as várias tentativas de reforma até então empreendidas, inclusive, imprimindo seus interesses no marco regulatório vigente. Apesar disso, tal posição vem dificultando a concertação de estratégias interfederativas para promover a gestão compartilhada dos serviços, tal como preconizado pelo STF, em 2013.

Nesse contexto, desde a redemocratização verificou-se apenas um reduzido crescimento da iniciativa privada que, atualmente, orbita no entorno de $6 \%$ do total da população atendida. Os dados reforçam a hipótese de que esse aumento de participação dos grupos privados está relacionado à uma retração da atuação municipal. Ademais, verifica-se que, em ambos os grupos - público e privado -, houve uma estagnação na ampliação dos sistemas de abastecimento de água, tendo sido o esgotamento sanitário o foco de investimento nos últimos anos. O resultado indicando que gestões estaduais e municipais tiveram o mesmo percentual de crescimento nesse setor permite aventar a hipótese sobre maior capilaridade dos recursos direcionados - em larga medida, pelo governo federal - para a execução da política pública. Ademais, a baixa participação do setor privado no Nordeste precisa ser estudada com mais detalhes a fim de permitir um melhor entendimento sobre esse quadro. Por fim, a partir dos dados também se constrói como hipótese que a elevada participação municipal nas regiões Sul e Sudeste está diretamente relacionada a melhores configurações institucionais e orçamentárias.

Após a crise político-financeira de 2014, em especial, a partir do impeachment de Dilma Rousseff, é possível sustentar que os atores sociais interessados na privatização do setor de saneamento teriam percebido esse momento de ruptura/instabilidade como uma janela de oportunidade política para, novamente, tentar incidir sobre as estruturas regulatórias do setor. Nesse momento, seus discursos buscavam convergir com aqueles que alertavam para o limite dos investimentos públicos, e para uma relativa estagnação na ampliação do atendimento de água e esgotos nos últimos anos. Nesse contexto, as tentativas de reformar o marco regulatório vigente vêm sendo rechaçadas e a recuperação das articulações entre estadualistas e municipalistas parece que, novamente, tem contribuído de forma decisiva para a disputa. No presente momento não está claro se a retomada das referidas alianças será suficiente para bloquear definitivamente as propostas de reforma, tal como na década de 1990. Isso porque, para além das inúmeras divergências no 
contexto político, econômico e social, há, uma vez mais, uma dissidência de parte dos governos estaduais interessados em absorver as ofertas de recursos privados, dificultando o processo de resistência. De todo modo, considerando a capacidade de articulação política já demonstrada por estadualistas e municipalistas, restam poucas dúvidas que a aprovação de qualquer proposta de mudança no marco regulatório, em especial, para ampliar as oportunidades de incidência do setor privado, dependerá de soluções concertadas e que incluam os referidos atores, caso contrário, vislumbra-se que tais proposições tenderão a enfrentar novos fracassos.

\section{REFERÊNCIAS}

ARRETCHE, Marta T. S. Política Nacional de Saneamento: A reestruturação das companhias estaduais. In IPEA, Instituto de Pesquisa Econômica Aplicada. Infra-estrutura: perspectivas de reorganização - saneamento. Brasília: Ipea, 1999. p.79-108.

BIER, Amaury G.; PAULANI, Leda Maria; MESSENBERG, Roberto P. A crise do saneamento do Brasil: reforma tributária, uma falsa resposta. Pesquisa e Planejamento Econômico, 18(1), Rio de Janeiro: IPEA, 1988. p. 161-196.

BORJA, Patrícia Campos; MORAES, Luiz Roberto Santos. O acesso às ações e serviços de saneamento básico como um direito social. XII SIMPÓSIO LUSO-BRASILEIRO DE ENGENHARIA SANITÁRIA E AMBIENTAL. Anais. Figueira da Foz: APRH/ABES, 2006. p.1-13.

BRAGA, José Carlos de Souza; MEDICI, André Cezar; ARRETCHE. Novos horizontes para a regulação do sistema de saneamento no Brasil. Revista de Administração Pública, 29(1), 1995. p. 115-148.

DANTAS, Felipe von Atzingen; LEONETI, Alexandre Bevilacqua; OLIVEIRA, Sonia Valle Walter Borges de; OLIVEIRA, Marcio Mattos Borges de. Uma análise da situação do saneamento no Brasil. FACEF Pesquisa: Desenvolvimento e Gestão, 15(3), 2012. p. $272-284$.

MOTTA, Ronaldo Seroa da. Questões regulatórias do setor de saneamento no Brasil. Notas técnicas. n. 5. Rio de Janeiro: Ipea, 2004. $28 \mathrm{p}$.

NOZAKI, Victor Toyoji de. Análise do setor de saneamento básico do Brasil. Dissertação (Mestrado em Economia Aplicada), Universidade de São Paulo, Ribeirão Preto, 2007. $109 \mathrm{f}$.

OLIVEIRA, Carlos Thadeu C. de; SANCHEZ, Oscar Adolfo. O setor de saneamento básico no Brasil e no Estado de São Paulo frente à descentralização político-administrativa. CEDEC, Centro de Estudos de Cultura Contemporânea. Cadernos Cedec n. 62. São Paulo: Cedec, 1997.

SANTOS, Alexandre. Descentralização e Municipalização: Habitação, Saneamento e Transporte. In Anais do Seminário: Municipalização de Políticas Públicas. Rio de Janeiro: Ipea, Ibam, Enap, 1993.

SANTOS, Angela Moulin Simões Penalva; VASQUES, Pedro Henrique Ramos Prado. Política urbana no contexto federativo brasileiro: um avanço normativo na gestão dos aglomerados urbanos. Revista Direito da Cidade, v.7, n.4, 2015. p. 1771-1790.

SOUSA, Ana Cristina Augusto de; COSTA, Nilson do Rosário. Ação coletiva e veto em política pública: o caso do saneamento no Brasil (1998-2002). Ciência \& Saúde Coletiva, 16(8), 2011. p. 3541-3552.

SOUSA, Ana Cristina Augusto de; COSTA, Nilson do Rosário. Política de saneamento básico no Brasil: discussão de uma trajetória. História, Ciências, Saúde. v.23, n.3, 2016. p.615-634.

TUROLLA, Frederico. A. Política de saneamento básico: avanços recentes e opções futuras de políticas públicas. Texto para Discussão n. 922. Brasília: Ipea, 2002. 29 p.

TUROLLA, Frederico Araujo; OHIRA, Thelma Harumi. Pontos para uma discussão sobre eficiência e regulação em saneamento. In: SALGADO, Lucia Helena; MOTTA, Ronaldo Seroa da. (Org.). Regulação e Concorrência no Brasil: governança, incentivos e eficiência. 1ed.Rio de Janeiro: IPEA, 2007, v. 2, p. 197-215.

VARGAS, Marcelo Coutinho; LIMA, Roberval Francisco de. Concessões privadas de saneamento no Brasil. Ambiente \& Sociedade. Vol. VII no. 2, 2004. p. 67-95.

Site www.snis.gov.br/, Diagnóstico Anual de Água e Esgotos. Consulta em 16/09/2019. 